\title{
"La estética de incertidumbre": la (in)certeza de la realidad en la novela Dios puso una sonrisa sobre su rostro de Winston Morales Chavarro
}

\author{
"The Esthetics of Uncertainty": The (Un)Certainty \\ of Reality in Winston Morales Chavarro's novel \\ Dios puso una sonrisa sobre su rostro
}

\author{
Barbara Curzytek \\ Uniwersytet im. Adama Mickiewicza w Poznaniu \\ barbara.curzytek@amu.edu.pl
}

\begin{abstract}
The article examines Winston Morales Chavarro's novel Dios puso una sonrisa sobre su rostro. It reflects on one of its principal themes: the limitations in the perception of reality, and attempts to determine the boundaries between the fantastic and the neofantastic elements in the novel. The purpose of the article is to show that one of the main ingredients of the novel is the neofantastic.
\end{abstract}

Keywords: fantasy, the neofantastic, Colombian literature, realism, perception in literature

\section{INTRODUCCIÓN}

En un trabajo de 2008, David Roas se pregunta si es posible hablar de literatura fantástica después de las teorías de la física cuántica: teorías como el principio de incertidumbre de Heisenberg han puesto en tela de juicio la percepción clásica de una realidad lógica, estable y racional. Y es la "estética de incertidumbre", ${ }^{\text {en pala- }}$ bras del escritor granadino Emilio Ballesteros, aquella que rige la novela de 2004

\footnotetext{
${ }^{1}$ Mantenemos el sintagma en su forma original, en que el sustantivo "incertidumbre" no va precedido de artículo.
} 
Dios puso una sonrisa sobre su rostro, del colombiano Winston Morales Chavarro. Dicha estética, igual que la teoría de Heisenberg, es explicitada por Ballesteros en el exordio a la obra. En el presente artículo analizaremos el criterio de percepción de la realidad en dicha novela, en un intento de responder a las siguientes preguntas: en qué medida el texto se inscribe en la vertiente neofantástica y si coincide con alguno de los rasgos del género fantástico clásico. Empezaremos presentando los conceptos de lo fantástico y lo neofantástico, teniendo en cuenta las reflexiones acerca del alcance de estos términos en el mundo postmoderno. Posteriormente, analizaremos la percepción de la realidad de parte del narrador-protagonista y la manera en que se trabaja el tema central de la obra: la muerte. Por consiguiente, serán significativos sus planteamientos en torno a la relatividad y la incertidumbre de la realidad cotidiana.

\section{LO FANTÁSTICO Y LO NEOFANTÁSTICO: APROXIMACIÓN TEÓRICA}

Si bien existen múltiples teorías acerca de lo fantástico, la mayoría de especialistas en el tema coinciden en que lo define la presencia de un elemento irreal, sobrenatural, ${ }^{2}$ misterioso o inexplicable que irrumpe en el mundo de la vida cotidiana considerado lógico y comprensible. Tal "convivencia conflictiva de lo posible y lo imposible"3 (Roas, 2008, p. 94) distingue a lo fantástico de otras modalidades afines, como lo maravilloso, donde lo preternatural o lo irracional es una parte inherente del mundo ficcional (Gregori, 2015). En esta última categoría entran tanto los antiguos cuentos de hadas como modalidades más modernas, entre ellas el surrealismo. Jaime Alazraki (1990) observa que la literatura fantástica es un producto del

\footnotetext{
${ }^{2}$ Alfons Gregori (2015) pone ciertos límites al uso del adjetivo "irreal", argumentando que "lo imposible, si está representado en el texto, tiene existencia (ficcional) y no puede ser (ficcionalmente) irreal" (p. 32). Asimismo, propone el uso del adjetivo "preternatural" como forma más neutra que "sobrenatural", en la que el prefijo indica una jerarquía -algo que es superior a la naturaleza-, además de la vinculación ideológica de este término con lo religioso. En cambio, "«preternatural» remite a elementos o fenómenos que tienen su origen o causa fuera de la naturaleza, a acciones que superan la naturaleza material conocida de nuestro mundo, a hechos paranormales de difícil explicación" (Gregori, 2015, p. 32). Tal enfoque indica la equiparación de ambos planos -el cotidiano y el que es la fuente de hechos paranormales-. Sin embargo, el propio uso de la raíz "natural" parece remitir a un mundo ordenado, lógico y perceptible de modo objetivo mediante un conjunto de leyes; y es preciso tener en cuenta que, de acuerdo con las teorías contemporáneas de la física y el cuestionamiento postmoderno de la visión científicamente objetiva procedente de la Ilustración, lo "natural" puede ser diferente en función del sujeto, tema que será desarrollado a continuación. Por lo tanto, puesto que el objeto del presente texto es la percepción de la realidad, nos referiremos a lo "irracional" o "inmaterial", es decir, aquello que es ajeno a la razón y a la realidad perceptible (pero posiblemente explicable y comprensible mediante otros sentidos; tal percepción puede - una vez más- variar en función del individuo).

${ }^{3}$ En este caso, la cursiva es del original.
} 
desarrollo de la ciencia, con sus explicaciones puramente racionales, por lo cual "nace en el momento en que cada uno está más o menos persuadido de la imposibilidad de los milagros" (p. 25). Por lo tanto, según observa el crítico, para el sujeto del texto fantástico la transgresión de las reglas racionales produce angustia, desasosiego o miedo. Y es a la categoría del miedo a la que recurre Alazraki a la hora de definir el relato fantástico clásico, que vincula con el romanticismo. A su entender, se trata de los relatos del siglo XIX que pretenden provocar en el lector miedo o terror. En cambio, a partir de La metamorfosis (1915) de Kafka empezaría una tendencia -posteriormente influida también por las vanguardias y el psicoanálisis-, que, más que "devastar la realidad conjurando lo sobrenatural", pretende indagar una realidad más allá de aquella construida racionalmente ${ }^{4}$ (Alazraki, 1990, p. 28). Esto es lo que el investigador entiende por relato neofantástico:

Si lo fantástico asume la solidez del mundo real [...], lo neofantástico asume el mundo real como una máscara, como un tapujo que oculta una segunda realidad que es el verdadero destinatario de la narración neofantástica. La primera [estética] se propone abrir una "fisura" o "rajadura" en una superficie sólida e inmutable; para la segunda, en cambio, la realidad es [...] una superficie llena de agujeros como un colador y desde cuyos orificios se podía atisbar, como en un fogonazo, esa otra realidad. (Alazraki, 1990, p. 29)

A esta definición corresponde el concepto de lo fantástico que expone Julio Cortázar en su conferencia "El sentimiento de lo fantástico" -a quien recurre numerosas veces el crítico-, aunque no utilice explícitamente el término "neofantástico". Para el escritor, lo fantástico es el sentimiento de extrañamiento: "el sentimiento de estar inmerso en un misterio continuo" (Cortázar, 1982). Sin embargo, ese sentimiento es para él algo natural: acepta la posibilidad de irrupción o presencia de otros mundos en una realidad que se da por objetiva. El autor argentino recurre al ejemplo de un cuento cuyo protagonista sueña una pesadilla y resulta que su realidad verdadera es la de la pesadilla, mientras lo que daba por su vida real no era más que un sueño. Así, "la narración neofantástica genera una nueva realidad a partir de un hecho inverosímil que se transforma en verosímil, pues el lector lo acepta e integra en su realidad" (Morales Benito, 2011, p. 133). Por consiguiente, no se produce el conflicto entre lo posible y lo imposible propio del relato fantástico clásico, en el que "tanto el lector como los personajes están sometidos a las normas que impone la verosimilitud racional de lo narrado" (Mariño Espuelas, 2008, p. 46).

Es preciso mencionar, además, la teoría de lo fantástico de Tzvetan Todorov, que se ha convertido en la más conocida. Para el estudioso, "lo fantástico es la

\footnotetext{
4 "Y si todo el mundo de Kafka obedece a una lógica onírica [...], esas imágenes surreales no han sido acuñadas para provocar miedos o terrores sino para cartografiar esa realidad segunda [...]" (Alazraki, 1990, p. 28).
} 
vacilación experimentada por un ser que no conoce más que las leyes naturales, frente a un acontecimiento aparentemente sobrenatural" (Todorov, 1981, p. 19), proponiendo dos soluciones de dicha vacilación: o bien el hecho sobrenatural es tan sólo un producto de la imaginación, o bien se ha producido realmente con base en unas reglas desconocidas para el sujeto, pero que forman parte de su realidad (Todorov, 1981, pp. 18-19). Así, para el teórico franco-búlgaro, sólo un conjunto fijo de leyes puede servir para medir la realidad. Esta definición es puesta en cuestión por Gregori (2015), quien considera que el sujeto en la visión todoroviana

no tiene creencias de ningún tipo más allá de su conocimiento -que no convencimientode unas leyes corroboradas mediante el método hipotético-deductivo de las ciencias experimentales [...], que además se vinculan necesariamente con el principio de causalidad y, por ello, con la lógica clásica o convencional. (p. 37)

Así, Gregori (2015) llega a plantear que Todorov peca de "ingenuidad cientificista" y de ignorar "las creencias humanas no comprobables" (p. 38). Además, hoy en día, aparte de las leyes clásicas, es preciso tener en cuenta las teorías de la física moderna que evoca David Roas (2008): "uno de los conceptos más cuestionados en las últimas décadas es la noción de realidad [...]" (p. 95). Como ejemplo indica, en primer lugar, la teoría de la relatividad de Einstein, que niega una percepción universal del tiempo y del espacio. Posteriormente, trata acerca de lo aleatorio de la mecánica cuántica y aquello que marca la percepción de la realidad de una manera quizás más significativa: el ya mencionado principio de incertidumbre de Heisenberg. En términos físicos, explica Roas (2008), dicho principio postula que

es imposible medir simultáneamente la posición y la velocidad de una partícula subatómica, puesto que para iluminarla es necesario al menos un fotón, y ese fotón, al chocar con la partícula alterará su velocidad y trayectoria en una cantidad que no puede ser predicha. (p. 96)

Así, añade Roas, el observador modifica con su intervención aquello que observa. Por tanto, "la realidad deja de ser objetiva y «externa», pues se ve profundamente afectada por el individuo que interacciona con ella" (p. 96). Esta postura parece más moderada que la de George Berkeley, quien a principios del siglo XVIII, en su Tratado sobre los principios del conocimiento humano, ${ }^{5}$ negaba la existencia de la materia apoyándose en la subjetividad de la percepción. Para el filósofo existir era ser percibido, por lo cual aquello no percibido no existía independientemente del sujeto (Berkeley, 2017). Sin embargo, como se verá más adelante, el narrador de la novela Dios puso una sonrisa sobre su rostro no niega la existencia de la materia, sino que considera que esta es el punto de partida para descifrar una segunda realidad.

\footnotetext{
${ }^{5}$ A Treatise Concerning the Principles of Human Knowledge, publicado por primera vez en 1710.
} 
Un fenómeno similar a las observaciones de Heisenberg se da en la paradoja de Schrödinger: la indeterminación cuántica se resuelve tras la intervención del observador. Así, la mecánica cuántica renuncia de la visión de una única realidad objetiva y medible, dejando lugar a varias dimensiones o realidades que coexisten simultáneamente y son igual de reales (Roas, 2008). Según afirma Michio Kaku, evocado por Roas, esas realidades no interactúan ni pueden influirse mutuamente puesto que sus ondas vibran en frecuencias diferentes. Roas observa, además, que la mecánica cuántica y la teoría de la relatividad son incompatibles y que el mundo subatómico se rige por unas leyes distintas que las del mundo macroscópico. Todo esto conforma una realidad subjetiva e inestable. Puesto que lo macroscópico parece regirse por las reglas de lo racional, mientras que el nivel cuántico es relativo, Roas extrae la conclusión de que sigue produciéndose el efecto fantástico. Sin embargo, parece necesario preguntarse si es posible que este se produzca en tales condiciones si, según argumenta Michio Kaku, las realidades no coinciden. Más bien podría considerarse que el efecto fantástico se produce cuando el sujeto que observa se guía únicamente mediante la razón y no admite la posibilidad de lo aparentemente imposible. Sin embargo, según ya hemos señalado, las sensibilidades de los individuos varían; de ahí que posiblemente pueda hablarse del efecto fantástico cuando el sujeto se halla frente a una situación que no puede explicar mediante ninguno de los métodos o sentidos que conoce o admite.

Desde el punto de vista de la neurobiología, la realidad tampoco parece objetiva para todos, como asevera Damasio: "las imágenes que experimentamos son construcciones cerebrales provocadas por un objeto y no imágenes especulares del objeto" (Roas, 2008, p. 99). Así, en la visión que de Damasio nos ofrece Roas (2008), "la realidad es concebida como una construcción "subjetiva», pero a la vez ésta es compartida socialmente" (p. 100). Es decir que no niega una realidad común. Asimismo, Roas (2008, p. 100) enumera a diversos filósofos constructivistas -Nelson Goodman, Jerome Bruner y Paul Watzlawick- que, de modo similar a Berkeley, "[...] postulan que la realidad no existe antes de la conciencia que nosotros tenemos de ella, lo que la convierte en una construcción subjetiva". Así, Goodman sostiene que no conocemos el mundo sino las "versiones" que fabricamos de él: "la percepción participa en la elaboración de lo que percibimos" (Roas, 2008, p. 100).

De ahí que se pueda observar el debilitamiento de la convicción acerca de una sola realidad objetiva y perceptible de manera unívoca. En cambio, se tiende a favorecer, en primer lugar, el papel de la percepción personal y diferentes sensibilidades: cada individuo observa la realidad a su manera. Por lo tanto, el efecto fantástico no depende de lo explicable mediante las reglas objetivas o comunes del mundo racional, sino que se produce en función de la sensibilidad de un individuo concreto. En segundo lugar, se abre espacio a la posibilidad de más de una realidad; lo clasificado antes como "irreal" puede coexistir con el plano conocido o tangible, y no necesariamente irrumpir bruscamente en lo "real". Analógicamente, la mecánica cuántica 
es real en la misma medida en que lo es el mundo macroscópico, a pesar de que funcionen en frecuencias diferentes, ${ }^{6}$ según los planteamientos de Kaku (v. 2008, pp. 199-201). En suma, la realidad es subjetiva y diferente para cada sujeto que la observe (aunque eso no niega la existencia de la materia). Cada individuo tiene su propia sensibilidad y su propia manera de percibir la realidad. Así, lo inexplicable mediante la razón, el único criterio tradicionalmente vigente, puede resultar explicable mediante otros medios. De este modo, lo antiguamente llamado "sobrenatural" no debe forzosamente provocar tensión y producir el efecto fantástico, al menos en el ámbito literario.

\section{LA ESTÉTICA DE LA INCERTIDUMBRE EN DIOS PUSO UNA SONRISA SOBRE SU ROSTRO}

La subjetividad de lo real desempeña un papel principal en Dios puso una sonrisa sobre su rostro. La novela carece de una trama desarrollada, estando constituida mayormente por reflexiones y recuerdos del narrador homodiegético. Desconocemos su nombre, aunque sabemos que trabaja en una morgue en Neiva, ${ }^{7}$ ciudad natal del autor, y que está casado, pero la relación con su esposa está llena de incomunicación e indiferencia. El espacio representado en la novela es verosímil: se mencionan calles y lugares concretos de la ciudad. Un día llega a la morgue el cuerpo de una muchacha joven de nombre desconocido, NN. En su maleta están los discos de la banda anglosajona Coldplay y las cartas de la chica a su padre escritas desde Irlanda, donde ella realizaba una investigación sobre W. B. Yeats. Los discos y las cartas delinean la estructura de la novela: el texto está compuesto de nueve capítulos y cada uno de ellos se divide en partes más breves numeradas. Los títulos de los capítulos principales son nombres de canciones de Coldplay, terminando cada uno con una carta de la muchacha muerta. El propio título de la novela es la paráfrasis traducida de una canción de Coldplay, "God put a smile upon your face". Francisco Javier Cubero (2011) afirma que la música no es imprescindible para una lectura adecuada de la novela. Sin embargo, un investigador que conozca la obra poética de Morales Chavarro puede darse cuenta de que en ella es frecuente el tema de la relación pitagórica entre música y cosmos. Puesto que se trata de una novela que aborda principalmente el tema de la existencia y la muerte, la música es seleccionada como un hilo narrativo que envuelve el texto. La elección de la banda Coldplay parece explicarse en la séptima carta de la muchacha: "He hallado mucha relación entre la escritura automática y Coldplay. A veces pienso que son unos posesos. Su noción de muerte, espacio y tiempo es bastante peculiar" (Morales

\footnotetext{
${ }^{6}$ Con todo, resulta discutible la falta de influencia entre ambos niveles.

${ }^{7}$ Ciudad en el suroeste de Colombia, capital del departamento de Huila.
} 
Chavarro, 2015, p. 130). ${ }^{8}$ La escritura automática se vincula con una preeminencia menor de la razón y con la predilección por lo inconsciente. Asimismo, la relatividad y la muerte, asociada esta con otra(s) realidad(es), son los principales temas de las reflexiones del narrador.

El tema central se anuncia desde las primeras líneas del texto, haciendo que el narrador trabaje en una morgue que se menciona al principio del primer capítulo:

Sparks suena de manera poco usual en la morgue. El sonido, proveído de cierta extrañeza por el frío de la sala, no es sonido porque sea perceptible, sino por las impresiones que despierta; ningún sonido se recuerda por el eco, por el timbre o el volumen, eso es algo demasiado natural para ser substancial en la asonancia; el sonido es por la memoria, por los ángulos visitados al girar sobre un recuerdo que congenia con la resonancia musical o artificial del resorte auditivo. (Morales Chavarro, 2015, p. 16)

Se introduce, asimismo, la convicción del narrador acerca de la subjetividad de la percepción. Se indica la influencia de la memoria en la percepción: los recuerdos se anuncian como una parte significativa del relato y constituyen al sujeto como un filtro por el que necesariamente tiene que pasar la realidad observada. Por otro lado, se rechaza la importancia de los criterios a la hora de medir objetivamente con métodos científicos, tales como el timbre o el volumen en el caso del sonido. En vez de eso, se presta más atención a las sensaciones que este produce en el sujeto que escucha. La forma, es, por lo tanto, objetiva, mientras que al narrador le interesa la subjetividad:

Uno por lo general descansa su percepción sobre cosas bien objetivas: carne, forma, voluptuosidad. El color, el olor, la morfología táctil, los sonidos emitidos por las hebras de cabello, por la pulsación de unas cuerdas vocales, por la fricción de los dedos o el roce de los muslos son, en cambio, asunto de subjetividades. Eso es lo que siempre he buscado: mi propia subjetividad. Aquel delgado sonido que se esconde detrás de la aparente nada -en donde los ojos de la objetividad no llegan por estar embalsamados con el raciocinio de la inteligencia y la madurez del vivo- es lo que realmente me apasiona. (Morales Chavarro, 2015, p. 36)

Así, para el narrador, servirse únicamente de la razón es centrarse en la forma y suprimir aquello que está más allá de lo material y objetivo. En cambio, él pretende trascender lo objetivo, interesándole la dimensión cuya existencia es negada mediante la razón. Por consiguiente, se abre hacia la posibilidad de una percepción subjetiva, diferente a la limitada a la razón: la realidad física se amplía a la hora de la búsqueda de aquello que la trasciende. Tal vez por eso la esposa del narrador le repite en múltiples ocasiones: "Pareces un tipo de esos", refiriéndose a los muertos

\footnotetext{
${ }^{8}$ La obra de Coldplay siempre se ha caracterizado por el surrealismo. Por lo tanto, el uso de sus canciones puede indicar el interés del autor de la novela por este movimiento vanguardista.
} 
que vigila el protagonista. Este parece alejarse de la realidad de los vivos, tratando de aproximarse al más allá para ampliar su visión de la realidad. De ahí la fascinación por la muerte, que "no es un suceso terminal sino el acceso al traspatio de otras posibilidades [...]" (Morales Chavarro, 2015, p. 27). Dichas posibilidades pueden descubrirse mediante la indagación subjetiva. Así, si bien la muerte es el final -fin de lo físico y objetivo- a ojos racionales, no necesariamente tiene que serlo para aquellos que no se limitan a la razón y admiten otros modos de percepción. De esta forma, la dimensión invisible a lo racional se convierte en una parte completamente válida de la realidad. Lo simboliza el espejo que se encuentra en la morgue: ${ }^{9}$

El espejo era el único ornamento dentro de la sala. ¿Para qué un maldito espejo en la morgue?, recuerdo que preguntó el gerente del hospital, mientras yo buscaba una explicación lógica a sus reniegos. La angustia que ocasionaba la afirmación de mi mujer ["pareces un tipo de estos"] me llevó a "contemplarme" con insistencia en la superficie del recuadro. Si bien es cierto que en él hallaba una respuesta a mis fluctuaciones y temores, también es cierto que en el espejo encontraba un espacio extrafísico que se confundía con la suprageografía de un mundo al que muy pocos tenemos acceso. Llegué a concluir que el espíritu del muerto se escapaba por ese marco de cristal, cuyos reflejos traían a mi cabeza tantos recuerdos de infancia. (Morales Chavarro, 2015, p. 22)

En este fragmento cabe destacar dos cuestiones. En primer lugar, la indagación de lo irracional por parte del protagonista, quien ve el espejo como la posibilidad de acceder a otra realidad. Esto corresponde perfectamente a la definición de lo neofantástico de Alazraki. En segundo lugar, la observación del espejo trae a la mente del narrador recuerdos del pasado: la libre asociación de conceptos ligada a la escritura automática y al flujo de consciencia. No es casualidad, por consiguiente, que en la tercera carta de la muchacha muerta se recurra al Ulises de James Joyce y se cite un fragmento del monólogo de Molly Bloom "a propósito de tus [del padre de la muchacha] gustos por lo inconsciente" (Morales Chavarro, 2015, p. 65). El flujo de consciencia suprime el orden racional y deja al descubierto el objetivo de la búsqueda del narrador, o sea, aquello que está más allá de la superficie ordenada. La racionalidad y la inteligencia están determinados por la memoria, dice el narrador: "uno es solamente recuerdos o lo que cree de ellos" (Morales Chavarro, 2015, p. 146). Con ello parece indicar que la percepción subjetiva rige la realidad hasta tal punto que no se puede estar seguro ni de uno mismo. ${ }^{10}$ Asimismo, el hincapié en los

${ }^{9}$ El espejo, si se recurre por ejemplo a un texto tan clásico como Alicia en el País de las Maravillas, simboliza un portal entre dos mundos o dimensiones.

${ }^{10}$ Freud (1972) afirmaría en 1915: "Del mismo modo que Kant nos invitó a no desatender la condicionalidad subjetiva de nuestra percepción y a no considerar nuestra percepción idéntica a lo percibido incognoscible, nos invita el psicoanálisis a no confundir la percepción de la conciencia con los procesos psíquicos inconscientes objetos de la misma" (p. 2064). 
recuerdos está relacionado con el periodo de la infancia, cuya importancia fue esgrimida por Freud. La contemplación del espejo de la morgue justamente trae al narrador un recuerdo infantil, que parece una escena fantástica: relata que en su niñez no se reflejaba en el espejo y que su sombra siempre estaba separada de su cuerpo:

Mamá solía pararse conmigo frente al espejo antes de despacharme para la escuela. [...] Me percataba de que el espejo omitía mi presencia. ¿Dónde estaba yo? ¿En qué rincón del submundo me encontraba, toda vez que mi rostro desaparecía en las aguas inquietantes de los vidrios? Cuando regresaba a casa, después de una jornada fatigante de disertación escolar, percibía que mi sombra iba a cien o doscientos metros delante de mi cuerpo. Como estudiante nunca sobresalí en las ciencias naturales y exactas, por lo que no daba una solución puntual a ese fenómeno, pero imaginaba que así como mi rostro no aparecía en el espejo, tampoco el reflejo de mi sombra era preciso, pues deducía que el sol y la tierra eran vulnerables en su naturaleza y actitud cósmica. (Morales Chavarro, 2015, p. 23)

Sin embargo, se puede observar que el narrador no busca una explicación racional de lo inverosímil, siendo significativo que afirme no tener un conocimiento amplio de las ciencias exactas. En cambio, asume que eso se debe a la naturaleza del cosmos, es decir, parte de un hecho inverosímil, que se convierte en un elemento válido para explicar la realidad, como en el relato neofantástico. No pretende traducir el fenómeno al lenguaje racional: lo irracional es una parte inherente de su realidad. Por otro lado, parece imprescindible mencionar la vinculación de esta escena con el motivo del espejo en el pensamiento de Jacques Lacan: en la comunicación "El estadio del espejo como formador de la función del yo [je] tal como se nos revela en la experiencia psicoanalítica", presentada originalmente en 1949, el psicoanalista afirma que el ser humano es verdaderamente él mismo en la infancia, cuando no posee el concepto del yo y no percibe su autonomía frente al mundo, hasta el momento en el que se mira en el espejo y adquiere la consciencia de su individualidad (v. Lacan, 2013, pp. 99-105). Sin embargo, una vez la adquiere, deja de ser él mismo y pasa a estar determinado por las normas colectivas -o también la memoria, según diría el narrador de Dios puso una sonrisa sobre su rostro-, fase que se extiende hasta la muerte. Por tanto, el hecho de que el narrador no se refleje en el espejo puede indicar dicha fase de autenticidad. Más adelante afirma: "Mi rostro no ocupaba -ocupa- ningún espacio en el espejo pese a la posición que busco desde toda perspectiva y ángulo. Sin embargo, en él se refleja toda la atmósfera de la morgue [...]" (Morales Chavarro, 2015, p. 26). Así, deja explícito que tampoco en la edad adulta se refleja en el espejo (pero sí se refleja en él aquello que supone otra dimensión). Eso indicaría que no ha perdido la autenticidad o que pretende mantenerla, buscándola en la dimensión o las dimensiones a la(s) que conduce el espejo. El hecho de que la realidad de la morgue sí se refleje en el espejo pero que el 
narrador (su cuerpo físico) no vea en él su rostro puede indicar también que la realidad simbolizada por la muerte es más auténtica que la física, lo cual se inscribiría en el marco de lo neofantástico. El narrador afirma explícitamente que tal sensibilidad se debe a una escena de su infancia:

Una noche de 1974, cuando ni siquiera superaba los cinco años, me desperté a altas horas de la madrugada en busca de la bacinilla que reposaba en un flanco de la cama. Al rebasar el cuerpo de mis progenitores -yo dormitaba en medio de ellos- y al buscar la boca del bacín, me encontré con un enorme gato que bebía los orines. El felino saltó sobre el mesón de la cocina y para sorpresa mía se introdujo por la rendija del lavabo desapareciendo misteriosamente entre las sombras. Nunca conté esa visión a mis padres -ni siquiera a papá, quien apreciaría el incidente-, por lo que solamente hasta ahora, cuando miro las cosas con los ojos de lo supranormal, justifico este hecho como una cercanía con los mundos paralelos y la lógica de un universo indefinible.

Fue ese gato, esa aparición fantasmagórica lo que moldeó mi temperamento y mi ruina metafísica. (Morales Chavarro, 2015, p. 76)

Se trata de una escena casi onírica, surrealista, vista en el momento después de despertar, al borde del sueño y la vigilia, y vista además por un niño, con la presencia de la estética de lo extraño y lo repulsivo. Una vez más, el narrador no la racionaliza, sino que le parece natural la existencia de universos paralelos, la causa de su visión. $Y$ eso se debe a que nunca les contó esa escena a sus padres, quienes inmediatamente la habrían racionalizado. En la edad adulta, el narrador no racionaliza, puesto que no había sido "corrompido" por la visión del mundo lógico y ordenado. La convicción de que la percepción de la realidad debería ser racional es impuesta por el entorno. El niño es socializado para mirar con los ojos de la lógica y se olvida de la autenticidad -otra vez volvemos aquí, al mismo tiempo, a la teoría lacaniana. El hecho de adquirir consciencia de sí, es decir, verse en el espejo del psicoanalista francés o ser expulsado del paraíso, ${ }^{11}$ impone un conjunto de normas sociales -inclusive la racionalidad científica- que se convierten en un filtro para la percepción. Recuperar el paraíso es morir, de ahí la fascinación por la muerte en el sentido en el que esta simboliza una visión no racional y, por ende, más auténtica.

De ahí que el narrador rechace conscientemente los patrones colectivos: le interesa "la belleza irracional, aquella que es ingenua a pesar de sí misma", siendo esta a su parecer algo "posible desde la subjetividad" (Morales Chavarro, 2015, pp. 43, 125). Depende del sujeto que mira; por eso se subraya el papel activo del observador en la percepción de la realidad, enlazando explícitamente con las teorías de Heisenberg o de Schrödinger. Puesto que se aleja de la racionalización, le fascina lo mórbido y lo repulsivo relacionado con la muerte (ligada al mundo no racional):

\footnotetext{
${ }^{11}$ Hacia el fin de la novela el narrador observa que, gracias al (o por culpa del) pecado de Eva, el ser humano fue "desterrado [...] de la ignorancia" (Morales Chavarro, 2015, p. 153).
} 
Nada es comparable a la belleza de un muerto, nada alcanza el equilibrio de un organismo en estado de quietud y putrefacción. Además, la belleza cuanto más irracional, más compleja, más compacta y precisa. (Morales Chavarro, 2015, p. 33)

Este tipo de reflexiones se da a partir de la contemplación de la muchacha muerta de la morgue, en la que observa una particular belleza, nunca vista en una mujer viva. El narrador, rechaza, así, "las concepciones culturales, cosa que es bastante común en nuestro entorno, en donde lo más usado es lo práctico, lo predecible, lo vulgar" (Morales Chavarro, 2015, pp. 52-53) y le interesa lo que colectivamente suele considerarse como extraño, mórbido o repulsivo, puesto que

quien mira lo que cree es su perfección se obnubila, se obscurece su racionamiento y es invadido por un monstruo conceptual, por una lógica irracional llamada forma y tiempo. Los muertos, por el contrario, ya no creen ni necesitan el tiempo. (Morales Chavarro, 2015, p. 34)

Este fragmento aparece cuando el narrador evoca el mito de Narciso: el momento en que la figura mitológica mira su rostro en el agua se asemeja a la pérdida de la autenticidad al mirarse en el espejo en la teoría de Lacan (2013, pp. 99-105). El narrador afirma que Narciso fue bello hasta el momento de mirarse en el agua. Así, el momento de contemplarse en el espejo y adquirir autoconsciencia equivale también a adquirir consciencia acerca de "la forma y el tiempo", cayendo pues en el racionalismo y olvidándose del "paraíso", de la percepción precedente. En cambio, en la dimensión simbolizada por la muerte (¿descomposición de lo materialmente macroscópico y regreso al nivel cuántico?) la percepción es relativa. Ahora bien, no necesariamente tiene que tratarse del paraíso perdido, que sólo se puede recuperar con la muerte. El narrador afirma: "personalmente nunca me he afanado por reconquistar la bienaventuranza edénica" (Morales Chavarro, 2015, p. 77). La explicación de ello parece darse en un fragmento previo de la novela:

Hay una razón poderosa para creer que todo lo que gravita por el éter está sonando simultáneamente en algún lugar del cosmos; lo extraespacial y atemporal confluyen en la orilla inimaginable de las cosas y más que contradecirse interactúan. Todo queda flotando, todo ruido, todo eco, cualquier rumor, por más pequeño que sea, toda resonancia se repite en un número indeterminado de objetos; toda cosa queda untada del sonido como si se tratase de un ungüento o una pócima mágica que proporciona vida al oído colectivo de la coexistencia. (Morales Chavarro, 2015, p. 26)

Así, el narrador considera que, igual que el nivel cuántico y el nivel macroscópico, la dimensión racional y la dimensión otra $-\mathrm{o}$ varias dimensiones otrascoexisten, resultan inseparables, una abarca la otra y se influyen mutuamente, lo cual se inscribe en el marco de lo neofantástico. Esta tesis es contraria a la del ya mencionado Kaku, quien afirma -insistimos- que ambos niveles no pueden interactuar 
puesto que funcionan en frecuencias diferentes. El narrador de Dios puso una sonrisa sobre su rostro, por el contrario, tiene la visión del universo como una totalidad, como una red de dimensiones que coexisten y forman una red de interacciones. "[L]a muerte nos ama", dice, "la muerte crece con nosotros, ha delineado sus estrías en nuestro rostro" (Morales Chavarro, 2015, p. 29). Más adelante añade: "la muerte está en nosotros, crece en nosotros, se constituye en un sentido más del organismo" (Morales Chavarro, 2015, p. 36), lo cual es una personificación metafórica de que la dimensión no material forma parte inherentemente de aquello considerado racional; de ahí que no pueda producirse un efecto fantástico, a diferencia de lo argumentado por Roas. Asimismo, la muerte puede ser una metáfora de lo inconsciente, la parte oprimida por las normas colectivas, que el narrador quiere recuperar. Es más: el protagonista es consciente de que "el universo es cerebral, todo es una idea [...]" (Morales Chavarro, 2015, p. 77), negando la existencia de una realidad fija y mesurable, lo cual lo acercaría el planteamiento expresado en la filosofía de Berkeley. Sin embargo, podría discutirse si el narrador o la instancia autorial niegan por completo la existencia de una realidad material, puesto que en su ensayo Poéticas del ocultismo Morales Chavarro (v. 2008) expone que el mundo material posee un lenguaje cifrado, es decir, emite mensajes o señales a descifrar. De este modo, la realidad material es más bien un pretexto para indagar en el más allá; y de ahí que el narrador de la novela Dios puso una sonrisa sobre su rostro pretenda centrarse en que lo tangible y medible permite hacer descubrimientos acerca de la realidad otra. Esto se inscribe en la definición de lo neofantástico que propone Alazraki. La dimensión no material deviene objeto de interés, dado que "la racionalidad mentecata de nuestras «sabidurías» más comunes niega aquellas cosas que dan verdaderamente vida" (Morales Chavarro, 2015, p. 29). Así, la realidad no material o la percepción del narrador acerca de lo real adquiere un estatus ontológico más verídico que lo racional o material, cosa que se aproximaría de nuevo a lo neofantástico.

\section{CONCLUSIONES}

En el presente texto hemos tratado la relación entre dos modos de percibir la realidad, es decir, la científica clásica y su ampliación hacia lo extraracional, así como la presencia o no de efecto fantástico en la novela Dios puso una sonrisa sobre su rostro de Morales Chavarro, analizando la incertidumbre de la realidad. Hemos argumentado que, de acuerdo con las teorías modernas de la física y la neurobiología, hoy en día es cuestionable el concepto de una realidad perfectamente mesurable y predecible, por lo cual la aparición del efecto fantástico no depende de reglas racionales fijas, sino de cada sujeto observador en particular, puesto que la percepción es subjetiva y ya no tiene que limitarse únicamente a la ciencia clásica. 
El narrador del relato pretende trascender la realidad material y aparentemente objetiva, lo cual remitiría al platonismo. La realidad material equivaldría a las sombras en la cueva de Platón y trascenderla sería equiparable a regresar hacia la luz: eso permite ver las cosas en su plenitud, pues el componente únicamente material no da una visión completa de lo real. De ahí que el narrador se manifieste en contra de las normas colectivas, las normas objetivadas, y decida mantenerse en un plano subjetivo, guiándose por aquello que va más allá de lo empírico. La muerte simbolizaría una de las dimensiones coexistentes con la realidad material, con la cual interactuaría. Tanto la dimensión extranatural como la cuántica son imprevisibles y permanecen ocultas para aquellos que se rigen solo a tenor de la ciencia clásica. La novela Dios puso una sonrisa sobre su rostro no se inscribe en el marco de lo fantástico clásico, ya sea por la ausencia del elemento del miedo (siguiendo a Alazraki), ya sea por la falta de tensión científico-irracional (siguiendo aquí a Todorov). En definitiva, en la novela destacan los elementos propios de lo neofantástico: la realidad material es un pretexto para indagar acerca de otra dimensión de lo real, y acercarse a esta permite adquirir una visión más completa de la totalidad. Asimismo, en la novela aparecen algunas muestras de surrealismo que podrían constituir el tema para una investigación posterior. 


\section{REFERENCIAS BIBLIOGRÁFICAS}

Alazraki, J. (1990). ¿Qué es lo neofantástico? Mester, 19 (2), 21-33.

Berkeley, G. A Treatise Concerning the Principles of Human Knowledge. Consultado el 19 de marzo en http://www.earlymoderntexts.com/assets/pdfs/berkeley1710.pdf

Cortázar, J. (1982). El sentimiento de lo fantástico. [Conferencia dictada en la Universidad Católica Andrés Bello, en Caracas (Venezuela)]. Consultado el 2 de septiembre de 2017 en http://ciudadseva.com/texto/el-sentimiento-de-lo-fantastico/

Cubero, F. J. (2011, 12 de junio). El tiempo suspendido. Sobre Dios puso una sonrisa sobre su rostro de Winston Morales Chavarro. Winston Morales Chavarro. Consultado el 3 de septiembre de 2017 en https://winstonmorales.blogspot.com/2011/06/el-tiempo-suspendido-sobredios-puso.html

Freud, S. (1972). Obras Completas, VI (1914-1917) (L. López-Ballesteros, trad.). Madrid: Biblioteca Nueva.

Gregori, A. (2015). La dimensión política de lo irreal: el componente ideológico en la narrativa fantástica española y catalana. Poznań: Wydawnictwo Naukowe UAM.

Kaku, M. (2008). Universos paralelos: los universos alternativos de la ciencia y el futuro del cosmos (D. Udina, trad.). Gerona: Atalanta.

Lacan, J. (2013). Escritos, 1 (T. Segovia \& A. Suárez, trad.). Madrid: Biblioteca Nueva.

Mariño Espuelas, A. (2008). Entre lo posible y lo imposible: el relato fantástico. En T. López Pellisa \& F. Á. Moreno (eds.), Ensayos sobre ciencia ficción y literatura fantástica (pp. 40-54). Madrid: Asociación Cultural Xatafi \& Universidad Carlos III.

Morales Benito, L. (2011). La búsqueda de una nueva verosimilitud: literatura neofantástica y patafísica. Carnets, III, 131-146. Consultado el 2 de septiembre de 2017 en http://revistas. ua.pt/index.php/Carnets/article/viewFile/840/773

Morales Chavarro, W. (2008). Poéticas del ocultismo en las escrituras de José Antonio Ramos Sucre, Carlos Obregón, César Dávila Andrade y Jaime Sáenz. Bogotá: Trilce Editores.

- (2015). Dios puso una sonrisa sobre su rostro. Los Ángeles: Createspace Independent Publishing Platform.

Roas, D. (2008). Lo fantástico como desestabilización de lo real: elementos para una definición. En T. López Pellisa \& F. Á. Moreno (eds.), Ensayos sobre ciencia ficción y literatura fantástica (pp. 94-120). Madrid: Asociación Cultural Xatafi \& Universidad Carlos III.

Todorov, T. (1981). Introducción a la literatura fantástica (2a ed., S. Delpy, trad.). México: Premia. 